\title{
Cerebrospinal fluid concentration of fibronectin in meningitis
}

\author{
D Torre, C Zeroli, M Issi, G P Fiori, G Ferraro, F Speranza
}

\begin{abstract}
Fibronectin concentrations in the cerebrospinal fluid were assessed in 20 patients with acute meningitis using a turbidimetric immunoassay. A significant increase in fibronectin concentrations was observed in patients with bacterial meningitis; decreased concentrations were observed in patients with viral meningitis. The determination of fibronectin concentration in patients with bacterial meningitis may represent a useful marker in differentiating bacterial from viral meningitis.
\end{abstract}

Fibronectin is a large glycoprotein of the extracellular matrix with a molecular weight of about 420 . It is found in virtually all body tissues and fluids, and is involved in adhesion and phagocytosis. ${ }^{1}$ Adhesion is a mandatory step for leucocytes passing through the vascular endothelia and migrating to the site of inflammation. There are two major forms of fibronectin: one is found in the blood (circulating fibronectin); and the other is associated with the cell surface (cellular fibronectin). Kuusela et al showed that human cerebrospinal fluid contains fibronectin ${ }^{2}$ and they also found that cerebrospinal fluid fibronectin is immunologically indistinguishable from the plasma form. Very little is known about the fibronectin response in central nervous system dysfunctions. More recently, Rautonen et al observed that in children with acute lymphoblastic leukaemia a high fibronectin concentration in the cerebrospinal fluid at the time of diagnosis is associated with a poor prognosis and the subsequent appearance of central nervous system leukaemia. ${ }^{3}$

The measurement of this protein could be

Division of Infectious Diseases, Regional Hospital and $E$ and $S$ Macchi Foundation, 21100 Varese, Italy

D Torre

C Zeroli

G P Fiori

G Ferraro

F Speranza

Blood and

Immunotransfusional Centre, General

Hospital, Saronno,

Italy

M Issi

Correspondence to:

Dr Donato Torre, Division

of Infectious Diseases,

Regional Hospital, Viale Borri 57, 21100 Varese, Italy

Accepted for publication 19 February 1991 of some diagnostic and prognostic value in several other dysfunctions. Although fibronectin cannot be regarded as an acute phase protein, its determination in cerebrospinal fluid could help to obtain the correct diagnosis in patients with meningitis, particularly if antibiotic treatment has already been started.

\section{Methods}

Twenty patients were studied (13 men and seven women, mean (SEM) age $26 \cdot 6(24 \cdot 1)$ years) with acute meningitis and without any sign of shock or disseminated intravascular coagulation. The diagnosis of bacterial meningitis was based on isolation of pathogens from the cerebrospinal fluid. Streptococcus pneumoniae was isolated in five patients and Neisseria meningitidis, Haemophilus influenziae, Streptococcus zooepidemicus, $S$ suis, $S$ faecalis, and Staphylococcus epidermidis in one patient each. Cerebrospinal fluid samples were also collected from nine patients with acute aseptic meningitis. One patient developed meningitis during Epstein-Barr virus infection, and in six the infection complicated mumps. In two patients the aetiological agent was not identified.

Twenty five healthy normal subjects (13 men and 12 women, mean (SEM) age 35.2 $(20 \cdot 1)$ years) served as control group.

The fibronectin concentration in cerebrospinal fluid was determined by using a turbidimetric immunoassay (Boehringer Biochemica, Mannheim, Germany). Turbidimetric measurement of the antigen-antibody reaction was performed according to the principle of the end-point method. Samples from a given patient were all analysed at the same time and made in duplicate.

Data are expressed as mean and standard deviation. Data were evaluated by the MannWhitney $U$ test. The level of significance was $5 \%$.

\section{Results}

The results of this study are illustrated in the figure. The cerebrospinal fluid concentrations of fibronectin in patients with bacterial meningitis were significantly higher $(13.9(6.1) \mathrm{mg}$ $\left.1^{-1} ; \mathrm{p}<0.01\right)$ than those of the control group $\left(6 \cdot 7(1 \cdot 3) \mathrm{mg}^{-1}\right)$. On the other hand, the

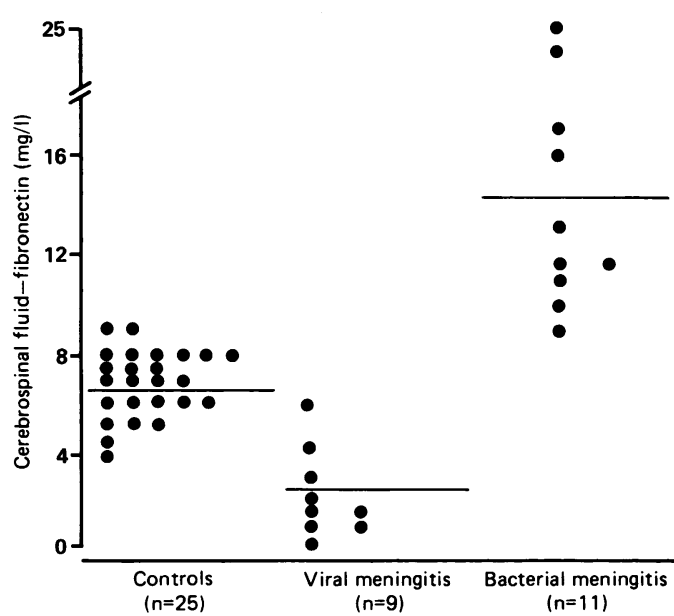

Fibronectin concentrations in cerebrospinal fluid of normal patients and those with bacterial and viral meningitis. Horizontal bars indicate mean fibronectin concentration. 
Fibronectin concentrations in cerebrospinal fluid of patients with bacterial meningitis

\begin{tabular}{|c|c|c|c|c|c|}
\hline \multirow[b]{3}{*}{ Case No } & \multicolumn{5}{|c|}{ Fibronectin $\left(m g l^{-1}\right)$} \\
\hline & \multirow[b]{2}{*}{ At admission } & \multicolumn{4}{|c|}{ Time since admission (days) } \\
\hline & & 5 & 10 & $15^{\star}$ & 30 \\
\hline $\begin{array}{l}1 \\
2 \\
3 \\
4\end{array}$ & $\begin{array}{l}16 \\
17 \\
25 \\
24\end{array}$ & $\begin{array}{l}15 \\
\text { ND } \\
\text { ND } \\
\text { ND }\end{array}$ & $\begin{array}{l}16 \\
\text { ND } \\
\text { ND }\end{array}$ & $\begin{array}{r}10 \\
9 \\
7 \\
6\end{array}$ & $\begin{array}{l}7 \\
\text { ND } \\
\text { ND } \\
\text { ND }\end{array}$ \\
\hline Mean (SD) values & $20 \cdot 5(4 \cdot 6)$ & & & $8 \cdot 0$ & \\
\hline
\end{tabular}

*This time represents the completion of antibiotic treatment and lumbar puncture control. to $<0.01$ when compared with basal concentrations. $\mathrm{ND}=$ Not determined. accumulated in the cerebrospinal fluid of patients with bacterial meningitis may be responsible for the increased cerebrospinal fluid concentrations. On the other hand, fibronectin binds to Staphylococcus aureus, Lancefield group A, C, and G streptococci, Streptococcus sanguis and Streptococcus pneumoniae. ${ }^{7-9}$ In this study, none of the cases of meningitis was produced by organisms that have previously been shown to bind fibronectin. It is conceivable, however, that fibronectin may bind to several other Gram positive and some Gram negative organisms. On the basis of our results, we are not able to determine whether binding of fibronectin by organisms isolated in our patients would result in lower cerebrospinal fluid concentrations.

The decreased concentrations of fibronectin observed in patients with aseptic meningitis could be due to the binding of fibronectin to viral proteins or to the virus itself. In fact, Julkunen et al showed that the glycoproteins of influenza $A$, parainfluenza 1 , and mumps viruses bound efficiently to fibronectin. ${ }^{10}$ As accumulation of polymorphonuclear neutrophils in the cerebrospinal fluid of patients with viral meningitis is rarely observed, de novo synthesis of fibronectin by polymorphonuclear neutrophils is probably not a factor. Thus fibronectin could represent a useful marker for differentiating bacterial from viral meningitis. Further studies will be needed, however, to clarify the role of fibronectin in the host response against bacterial or viral pathogens responsible for meningitis. with aseptic meningitis. Although the origin of fibronectin in the cerebrospinal fluid is not clear, several hypotheses could explain the increased concentrations of this protein in bacterial meningitis. The presence of fibronectin in the cerebrospinal fluid is at least partially the result of local production in the central nervous system. It seems feasible that fibronectin may be synthesised intrathecally as a reaction of tissue damaged by the infective process. Polymorphonuclear neutrophils are the major cell population in the acute inflammatory reaction of bacterial meningitis. Polymorphonuclear neutrophils can respond to a variety of stimuli and, on activation, emerge from the circulation and migrate to inflammed meninges. Furthermore, polymorphonuclear neutrophils retain the capacity to synthesise RNA and proteins in the nonactivated and activated states. ${ }^{4}$ La Fleur et al observed that fibronectin and its mRNA are synthesised by polymorphonuclear neutrophils, especially under conditions of activation. ${ }^{5}$ Kreis et al also showed that polymorphonuclear neutrophils isolated from the synovial fluid of patients with inflammatory arthropathies synthesise and secrete increased amounts of fibronectin. ${ }^{6}$ De novo synthesis of fibronectin by polymorphonuclear neutrophils concepts of its structure and functions. Coll Res $1981 ; 1: 95-128$.

2 Kuusela P, Vaheri A, Palo J, Ruoslahti E. Demonstration of fibronectin in human cerebrospinal fluid. $J$ Lab Clin Med 1978;92:595-601.

3 Rautonen J, Koskiniemi M, Siimes MA, Salonen EM, Vaheri A. Elevated cerebrospinal fluid fibronectin concentration indicates poor prognosis in children with acute lymphoblastic leukemia. Int J Cancer 1989;43:32-7.

4 Granelli-Piperno A, Vassalli JD, Reich E. RNA and protein synthesis in human peripheral blood polymorphonuclear leukocytes. J Exp Med 1979;149:284-93.

5 La Fleur M, Beaulieu AD, Kreis C, Poubelle P. Fibronectin gene expression in polymorphonuclear leukocytes: accumulation of mRNA in inflammatory cells. $\mathrm{J} \mathrm{Biol} \mathrm{Chem}$ 1987;262:2111-20.

6 Kreis C, La Fleur M, Menard C, Paquin R, Beaulieu AD. Thrombospondin and fibronectin are synthesized by rabbit model of in vivo neutrophil activation. J Immunol rabbit model of in

7 Kuusela P. Fibronectin binds to Staphylococcus aureus. Nature 1978;276:718-20.

8 Myhre EB, Kuusela P. Binding of human fibronectin to group A, C, and G streptococci. Infect Immun 1983;40 29-34.

9 Coutney HS, Ofek I, Hasty DL, Whitnack E, Simpson WA Mapping of the pneumococcal binding domain in human plasma fibronectin (abstract B39). In: Abstracts of the 85th Annual Meeting of the American Society for Microbiology. Washington, DC: American Society for Microbiology, 1987.

10 Julkunen I, Hautanen A, Keski-Oja J. Interaction of viral envelope glycoprotein with fibronectin. Infect Immun 1983;40:876-81.
1 Ruoslahti E, Engvall E, Hayman EG. Fibronectin: current 